\title{
Effect of mixing parameters on the mixing time and density of composite HA/Ti6AI4V feedstock for powder injection molding
}

\author{
Amir Arifin ${ }^{1, *}$, and Abu Bakar Sulong ${ }^{2}$ \\ ${ }^{1}$ Department of Mechanical Engineering, Faculty of Engineering, Sriwijaya University, 30662 Indralaya Indonesia \\ ${ }^{2}$ Department of Mechanical and Material Engineering, University Kebangsaan Malaysia, 43600 Bangi, Selangor, Malaysia
}

\begin{abstract}
Hydroxyapatite is a bioactive material. However, Hydroxyapatite in medical application is limited by its poor mechanical properties. Titanium alloys are biocompatible materials with high specific strength and high corrosion resistance. This combination can successfully be used in biomedical applications. The mixing process is a critical stage in the metal injection molding process because it determines the quality of the metal injection product. The homogeneity of the feedstock depends on the mixing parameters used during the mixing process. An experiment was conducted using Ti6Al4V and hydroxyapatite powder as feedstock at a mixing ratio of 60:40 wt $\%$. This feedstock was mixed with a mixture of polyethylene and palm stearin as the binder. The mixing parameters used in this study were the mixing speed $(10$ and $30 \mathrm{rpm})$ and the mixing temperature $\left(130^{\circ} \mathrm{C}\right.$ and $\left.150^{\circ} \mathrm{C}\right)$ at a powder loading of $67 \%$, as determined by the critical powder volume percentage experiment data $(69.5 \%)$. Increases in the mixing speed and mixing temperature reduced the mixing time to achieve homogeneity. The combined feedstock achieved the highest density at a mixing speed of $30 \mathrm{rpm}$ and a mixing temperature of $150^{\circ} \mathrm{C}$.
\end{abstract}

\section{Introduction}

Metal injection molding (MIM) is a combination of injection molding and powder metallurgical processes [1]. MIM is one of the near-net-shaped molding processes in manufacturing. The primary advantage of MIM compared with other methods is its low cost for mass-producing small and complex precision parts [2]. The MIM process has four stages: powder and binder mixing, injection molding, debinding, and sintering as shown on the Fig.1. Mixing is a vital stage that determines the homogeneity of feedstock quality in the MIM process. Deficiencies in feedstock quality cannot be corrected by the subsequent process. Failure to distribute powder uniformly on the feedstock can result in molding defects on the final product $[3,4]$. Nonhomogeneous feedstock can cause defects such as distortion, cracks, and voids in the sintered part. A number of factors affect the feedstock properties, such as the speed and mixing time, geometry of the mixing blades, temperature, particle characteristics, composition, and viscosity $[5,6]$.

Hydroxyapatite (HA) and titanium are key elements in the development of medical components [7]. HA or $\left[\mathrm{Ca} 10(\mathrm{PO} 4)_{6}(\mathrm{OH})_{2}\right]$ is a calcium phosphate ceramics currently used as a bioactive material for dental and orthopedic applications [8]. Its composition and structure is similar to those of bone, but with poor mechanical properties. On the other hand, titanium has high mechanical properties such as specific strength, corrosion resistance. Moreover in term of Young's modulus, titanium alloys has lower value than another metal implant and approaching of Young's modulus of the human bones. The unique properties of both materials can be suitably combined for medical applications. Feedstock have a considerable influence on the quality of products through MIM method. a homogenous feedstock will reduce some of defects such as porosity and cracks.

To obtain a homogeneous feedstocks need to consider the type and composition of the binder used. Generally component of binder can be categorized into two part;

$\checkmark$ Low molecular weight polymer; which has low temperature decomposition.

$\checkmark$ High molecular weight polymer ; which has relatively high temperature decomposition

Moreover a binder system on injection molding process is designed based on several functions such as backbone, surfactant and lubricant. In this work, polyethylene has functioned as the backbone. Palm stearin itself which is fraction of palm oil has fatty acid content play important role as surfactant and lubricant. Palm Stearin is a natural substance that is found in palm oil producing countries in the regions of Asia, Africa and Latin America such as Indonesia, Malaysia, Thailand, Colombia and Nigeria. Palm stearin as natural material will reduce the effects of environmental pollution. moreover the use of palm stearin as a binder can reduce cost incurred in buying commercial binder.

\footnotetext{
* Corresponding author: amir@unsri.ac.id
} 
The objective of this paper is to study the effects of the mixing parameters of a Ti6Al4V/HA composite with a palm stearin and polyethylene binder system on the mixing time and density.
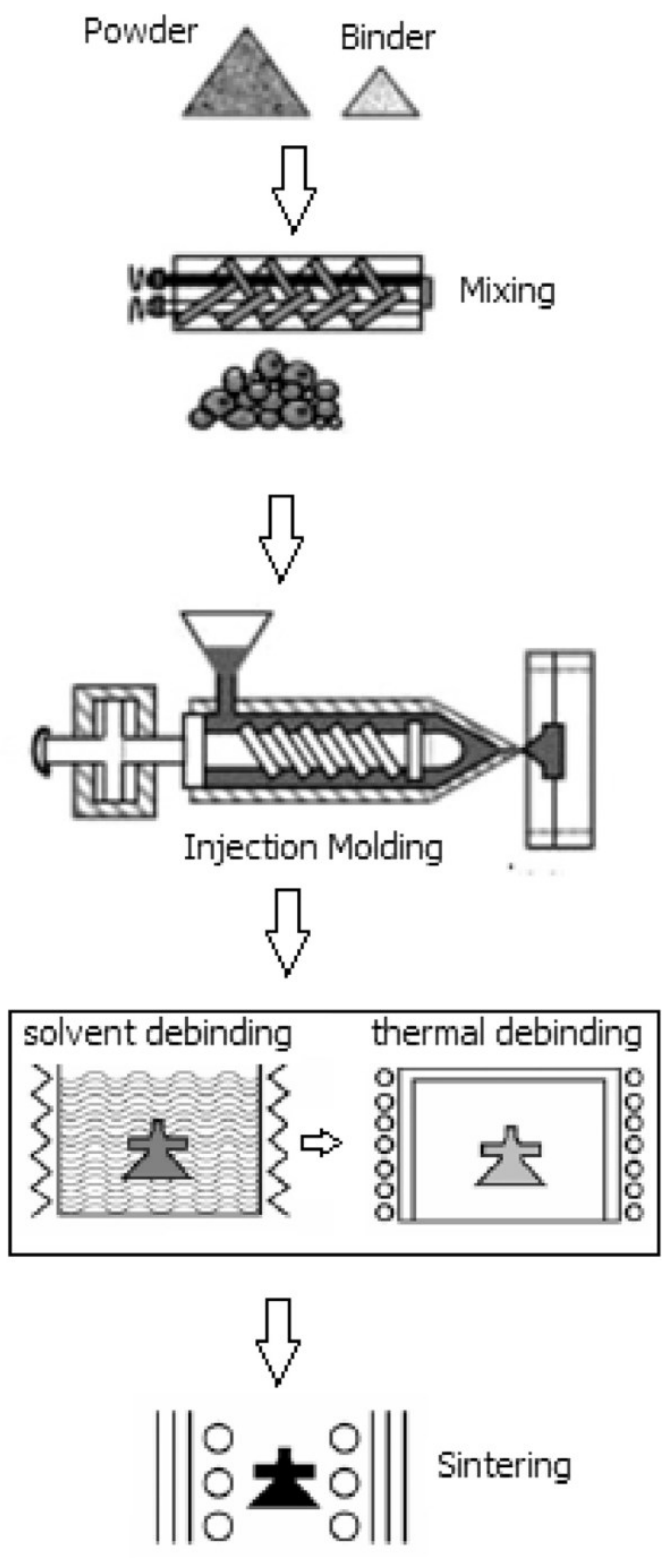

Fig. 1. Injection molding process scheme

\section{Experimental}

The Ti6Al4V powder used in this experiment was supplied by TLS Technik GmbH \& Co. It has an average particle size of $25 \mu \mathrm{m}$ and is spherical in shape (Figure 2). HA (Sigma-Aldrich Co., Germany) has an average powder size of $5 \mu \mathrm{m}$ (Figure 3 ). The HA powder, which is smaller than the titanium powder, HA powder is expected to fill gap between titanium powder.

The binder system consists of $60 \mathrm{wt} \%$ palm stearin and $40 \mathrm{wt} \%$ polyethylene. Differential scanning calorimetric results for palm stearin and polyethylene (Figures 5 and 6) has showed that the melting temperatures of palm stearin and polyethylene were $\sim 54$ and $\sim 125^{\circ} \mathrm{C}$, respectively. Mixing temperature of feed stock was determined by these results. The composite powder has a composition of $60 \mathrm{wt} \% \mathrm{Ti} 6 \mathrm{Al} 4 \mathrm{~V}$ and 40 wt $\%$ HA. Before composite powder Ti6Al4V/HA was mixed with palm stearin and polyethylene, premix was performed for Ti6Al4V and HA powder premixed using a Winkworth Sigma Blade Mixer for $0.5 \mathrm{~h}$ as shown on Figure 4. Premix stage is conducted to facilitate homogeneity of Ti6Al4V and HA powder.

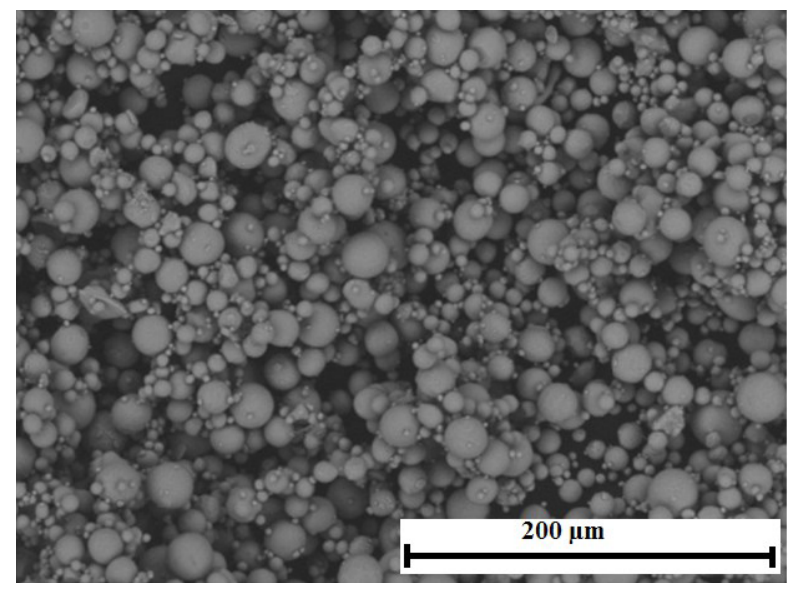

Fig. 2. Scanning electron micrograph of the Ti6Al4V powder.

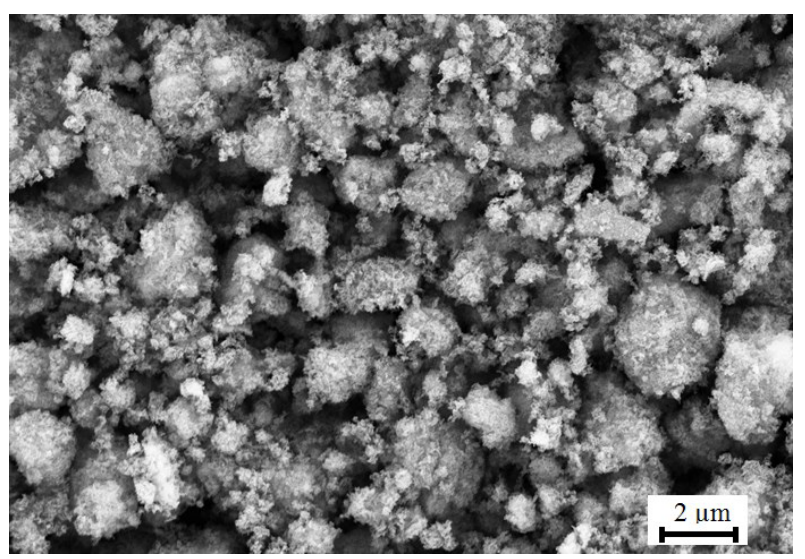

Fig. 3. Scanning electron micrograph of the hydroxyapatite (HA) powder.

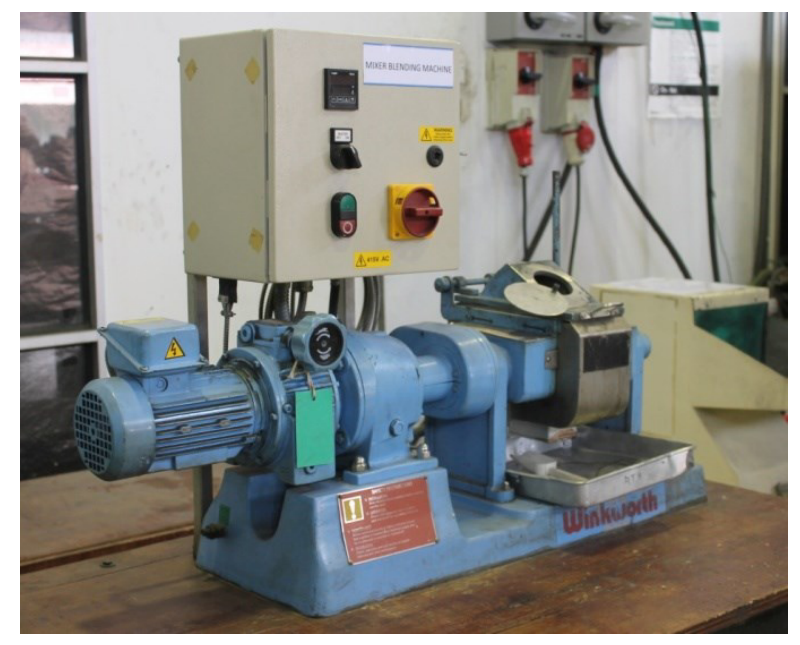

Fig.4. Winkworth Sigma Blade Mixer 


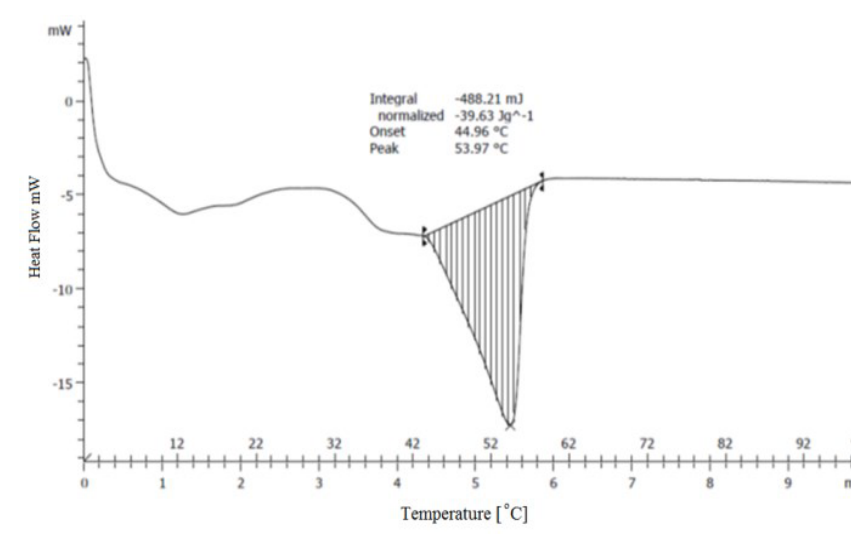

Fig. 5. Differential scanning calorimetric curve of palm stearin.

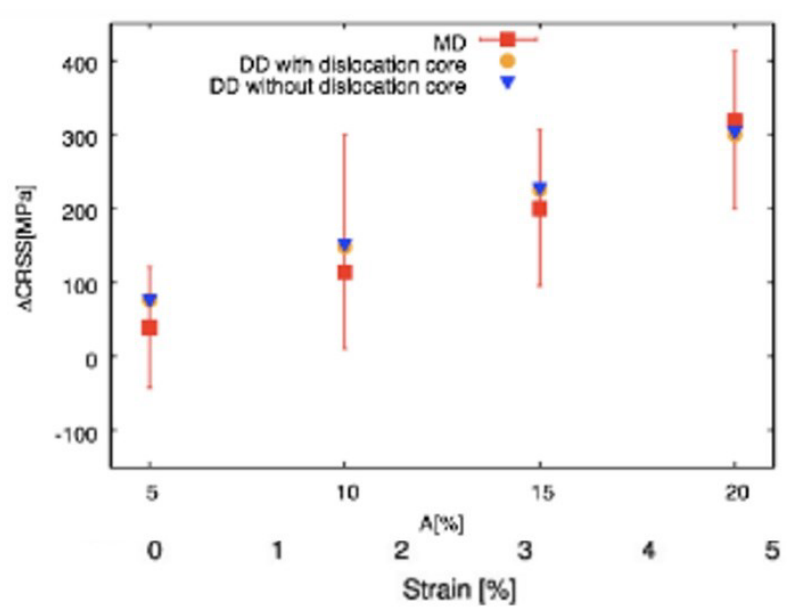

Fig. 6. Differential scanning calorimetric curve of polyethylene

The critical powder volume percentage (CPVP) of the mixture is measured using the oil absorption technique based on ASTM: D-281-12. Powder mixture was mixed with binder system for $30 \mathrm{~min}$ at $30 \mathrm{rpm}$. Firstly, polyethylene was melted completely in mixing machine,then palm stearin and followed by composite powder mixture of Ti6Al4Vand HA. The critical powder volume percentage (CPVP) of was obtain $69.5 \mathrm{vol} \%$, as shown by the maximum torque curves (Figure 8 ). Brabender W50EHT Measurement and Control Systems was used to analysis CPVP as shown on the Figure 7.

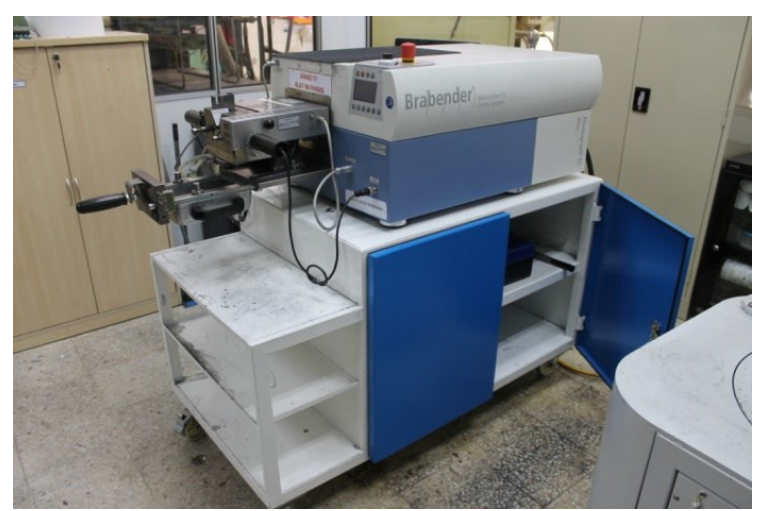

Fig. 7. Brabender W50EHT Measurement and Control Systems
According to German et al 1997, optimum powder loading for MIM ranged from $2 \%$ to $5 \%$, which is lower than the critical powder loading. In this study, $67 \mathrm{vol} \%$ was determined as the optimum powder loading.

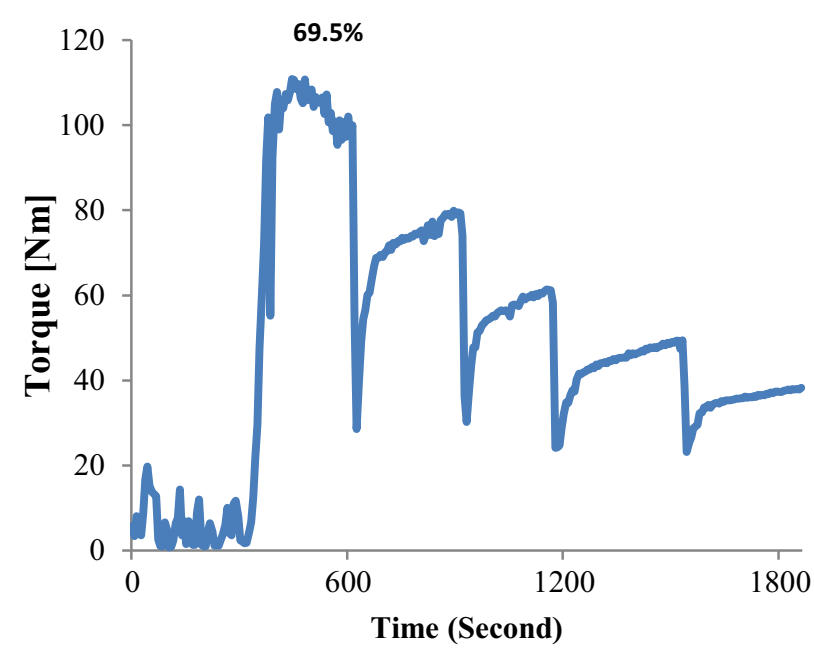

Fig. 8. Mixing process to determine the critical powder volume percentages (CPVP) of Ti6Al4V and HA powder.

All mixing parameters were analyzed using a Brabender mixer that consisted of a mixer backstand, a gear unit, and a mixer bowl. The mixing speed and mixing temperature were set based on the parameters shown in Table 1. The mixing process stops when the homogeneity of the feedstock reaches the value of a steady-state torque on the graph. The density of each sample was measured for comparison with the result of the Brabender mixing.

Table 1. Variations in the mixing parameters.

\begin{tabular}{|c|c|c|c|}
\hline Identification & $\begin{array}{c}\text { Powder } \\
\text { Loading vol } \\
(\%)\end{array}$ & $\begin{array}{c}\text { Mixing } \\
\text { Speed (rpm) }\end{array}$ & $\begin{array}{c}\text { Mixing } \\
\text { Temp }\left({ }^{\circ} \mathrm{C}\right)\end{array}$ \\
\hline $\mathrm{A} 6710130$ & $67 \%$ & 10 & 130 \\
\hline $\mathrm{A} 6710150$ & $67 \%$ & 10 & 150 \\
\hline $\mathrm{A} 6730130$ & $67 \%$ & 30 & 130 \\
\hline $\mathrm{A} 6730150$ & $67 \%$ & 30 & 150 \\
\hline
\end{tabular}

\section{Results and discussion}

Figure 9 shows the torque of the mixing process at different speeds and temperatures. In this process, the graph can be divided into three stages. In the first stage, the polyethylene was loaded into the chamber until it fully melted. The graphs remain stable, with a few fluctuations. In the second stage, large fluctuations in the torque values occur when the powder and the palm stearin was added. The number of peaks and the peak heights in the graph depend on the loading process of the powder and the palm stearin, which in turn affects torque. In the final stage, the feedstock reaches homogeneity with the torque and remains at the same 
value for each sample. Morover some peak of torque was observed on the Fig 9. Initial peaks on the graph was created due to the addition powder on the chamber. The

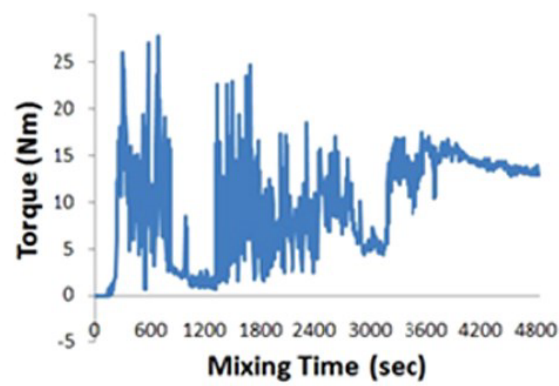

(a)

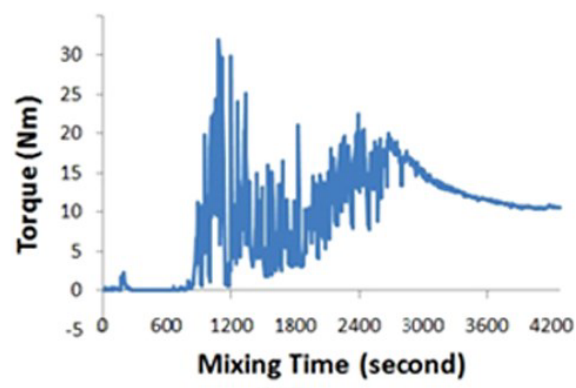

(c) last peak on the graph as indicator homogeneity of feedstock was started until graph constant.

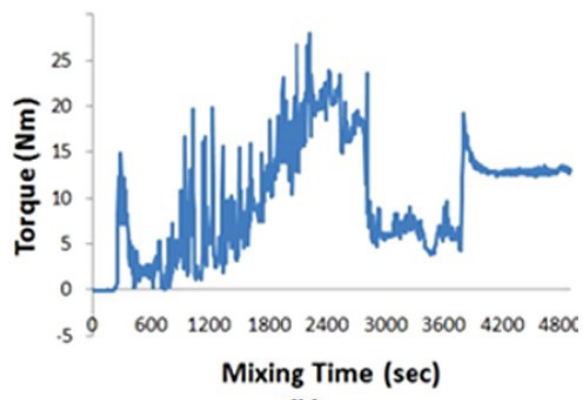

(b)

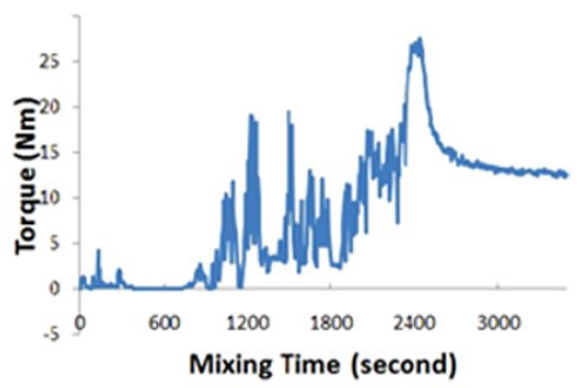

(d)

Fig. 9. Torque behavior of the feedstock under various mixing parameters.(a) A6710130, (b) A6730130, (c) A6710150 and (d) A6730150

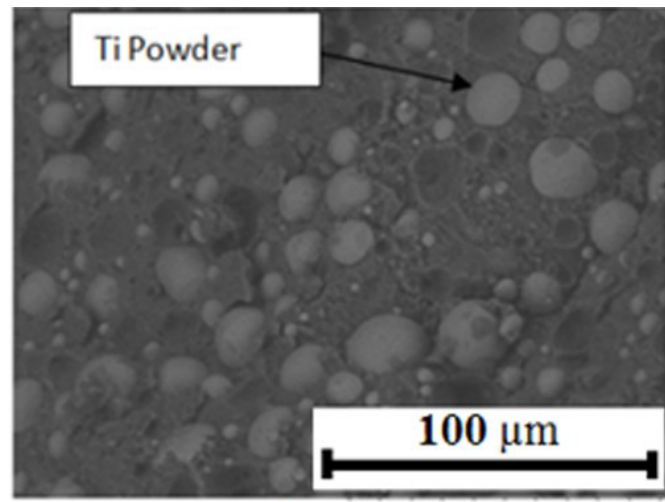

(a)

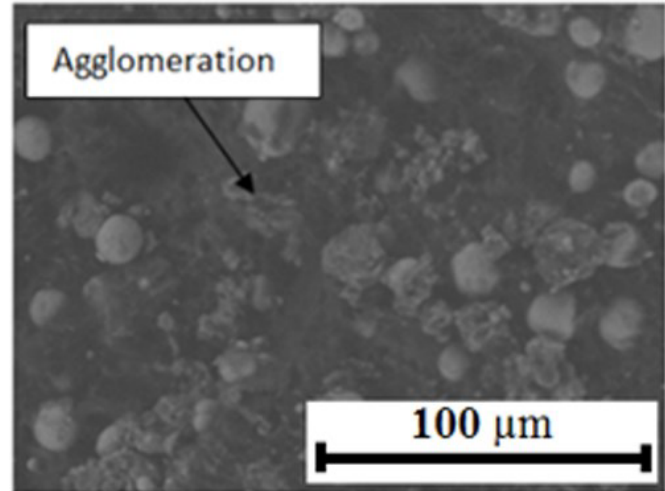

(c)

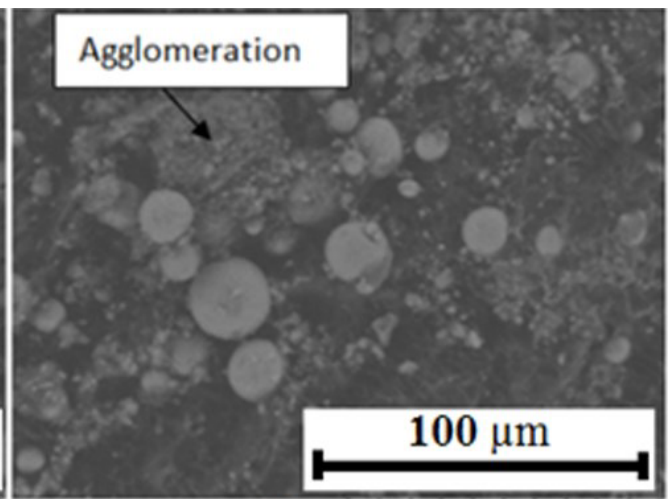

(b)

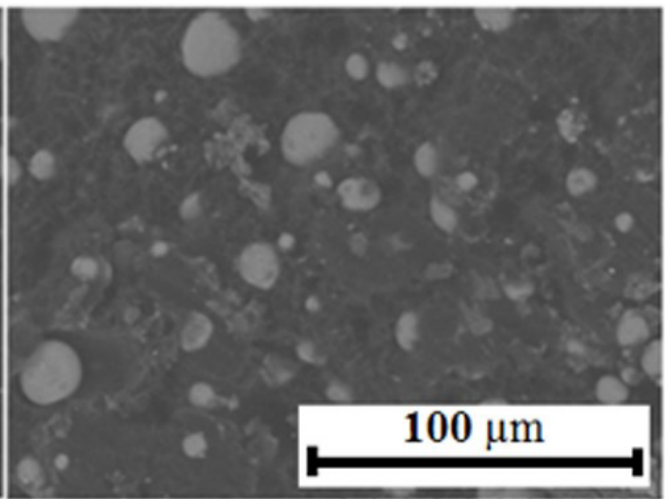

(d)

Fig. 11. Scanning electron micrograph of feedstock after mixing; (a). A6710130, (b) A6710150, (c) A6730130 and (d) A6730150 


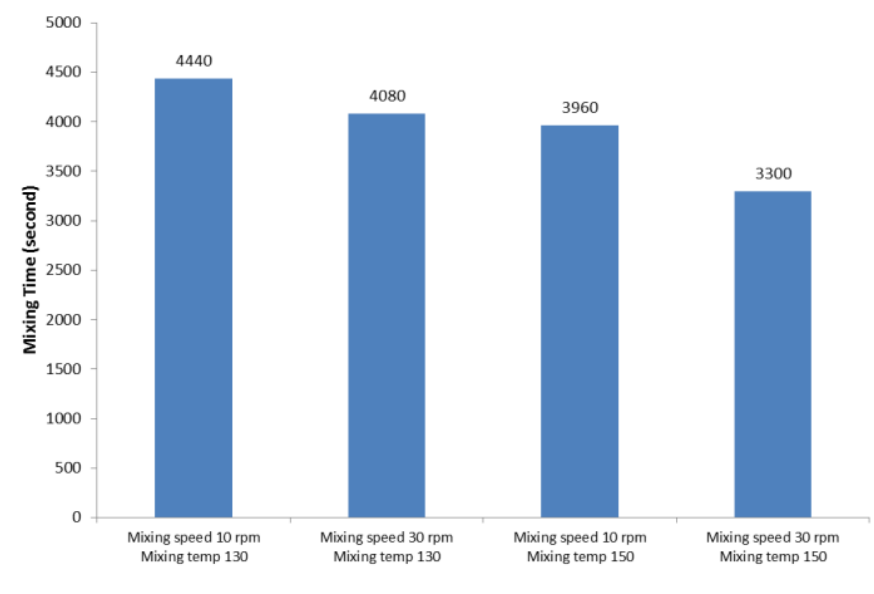

Fig.10. Mixing time of the feedstock at different mixing parameters.

Figure 10 shows that an increase in the mixing speed of the process from $10 \mathrm{rpm}$ to $30 \mathrm{rpm}$ reduced the mixing time required to reach homogeneity from $\sim 4,440 \mathrm{~s}$ to $\sim 4,080 \mathrm{~s}$ at a mixing temperature of $130^{\circ} \mathrm{C}$. At a mixing temperature of $150^{\circ} \mathrm{C}$, the reduction was from $\sim 3,960 \mathrm{~s}$ to $\sim 3,300 \mathrm{~s}$. Furthermore, an increase in the mixing temperature reduced the mixing time needed to achieve homogeneity. A6710130 showed the longest mixing time among all the composites. However, homogeneity was achieved by A6730150 at the shortest time (Figure 10). This result may be due to the combination of increased mixing temperature. In addition, the amount of input energy that was transferred from the mixer blade during shearing in the mixing process increased with the increase in speed.

Table 2. Bulk density of the feedstock.

\begin{tabular}{|c|c|c|c|c|}
\hline Sample & A6710130 & A6730130 & A6710150 & A6730150 \\
\hline $\begin{array}{c}\text { Density } \\
\text { g/cm }\end{array}$ & $2.52 \pm 0.02$ & $2.52 \pm 0.04$ & $2.53 \pm 0.04$ & $2.54 \pm 0.04$ \\
\hline
\end{tabular}

Density measurements were performed to determine the density and to investigate the homogeneity of the feedstock. Table 2 shows that each sample has a small standard deviation, indicating that the material achieved homogeneity. At the $150^{\circ} \mathrm{C}$ mixing temperature, an increase in the mixing speed increased the density. However, the density at the mixing temperature of $130^{\circ} \mathrm{C}$ appeared stable. A6730150 has the highest density, which is due to the combined increase in the mixing speed and the mixing temperature as a result of the viscosity effect of polyethylene, which has a melting point of $125^{\circ} \mathrm{C}$. The viscosity of polyethylene decreased at higher temperatures, which facilitated the mixing.

Agglomeration is the buildup of powder with a powder which is a common phenomenon, especially in the powder at the nanometer scale. Agglomeration is avoided in the powder metallurgy process due to produces a lack of uniformity that results in defects in the final product.

Figure 11 shows, Scanning electron micrograph of feedstock under various mixing parameters. Agglomeration appears on the figure 11 (b), (c) and (d). Although agglomeration was not occurring on Fig 11 (a) but there were groups of titanium powder tend to close if comparing with other Figure $8(\mathrm{a}, \mathrm{b}$ and $\mathrm{c})$. Titanium powder tend to distribute as shown on Figure 11 (a,b and c) but there were agglomeration especially on Figure 11.(b) and Figure 11(c). Agglomeration tends to decrease with the increasing of mixing speed and mixing temperature. In this term can be concluded that the increase in mixing speed has significant impact on the quality of the resulting feedstock. However high speed on the mixing speed will lead to air trapped in the feedstock. furthermore mixing temperatures can reduce the viscosity of the binder that facilitates the process of achieving uniformity of feedstock. Based on the results of Scanning electron micrograph on feedstock after mixing, agglomeration was found in the composite powder Ti6Al4V / HA. this happens is believed due to differences in size, shape and nature of the powder used.

\section{Conclusion}

Mixing analysis process for composite powder HA/Ti6Al4V has been performed. Some parameter process of mixing has been analysis such as mixing time and density of feedstock. Experiment results showed that the increasing of mixing speed and mixing temperature tend to reduce the mixing time needed to attain feedstock homogeneity. In addition, the density results show that a mixing speed of $30 \mathrm{rpm}$ and mixing temperature of $150 \mathrm{C}$ are the optimal parameters for obtaining the optimum mixing time and density.

\section{References}

1. German, R.M. and A. Bose, Metal Powder Industries Federation.

2. Heaney, D.F., J.D. Gurosik, and C. Binet, Journal of Materials Science, 2005. 40(4): p. 973-981.

3. Huang, B., S. Liang, and X. QuJournal of Materials Processing Technology, 2003. 137(1-3): p. 132-137.

4. Liu, Z.Y., et alMaterials Characterization, 2002. 49(4): p. 313-320.

5. Niespodziana, K., et al., Materials Chemistry and Physics, 2010. 123(1): p. 160-165.

6. Pramanik, S., et al., Ceramics International, 2007. 33(3): p. 419-426.

7. Sopyan, I., et al., Science and Technology of Advanced Materials, 2007. 8(1-2): p. 116-123.

8. Gunawan, et al., Key Engineering Materials, 2012. 531532: p. 258-261.

\footnotetext{
* Corresponding author: amir@,unsri.ac.id
} 